\title{
GERONTECHNOLOGY - NEW OPPORTUNITIES IN THE SERVICE OF OLDER ADULTS
}

pages: $114-126$

\author{
KATARZYNA HALICKA DARIUSZ SUREL
}

\begin{abstract}
A B S T R A C T
The increasingly more visible trend of population ageing necessitates creating technologies supporting the functioning of older adults. Consequently, more gerontechnologies emerge designed to help the older adults in their daily functioning, from devices monitoring the health to special trolleys improving the mobility or Virtual Reality devices for active learning. This article aimed to determine the most desired group of gerontechnologies among current and future users. It focused on individual assessments of the most desirable group of gerontechnologies based on various criteria. The investigation aimed to find the criterion rated the highest in the selected group of gerontechnologies. The gerontechnology group was assessed against seven groups of criteria distinguished by the authors, i.e., Technology Innovation, Technology Demand, Social and Ethical Criteria, Technology Usability, Technology Functionality, Technology Ease of Use and Technology Use Risk. The survey was conducted in the form of a questionnaire, using CAWI (Computer-Assisted Web Interview) and CATI (Computer-Assisted Telephone Interview) methods, with the research sample comprised of 1152 residents of Poland. Thus far, no studies have been conducted to evaluate this group of technologies based on the above-mentioned criteria.
\end{abstract}

KEY WORDS

gerontechnology, technology, health, analysis, older adults

10.2478/emj-2021-0025
Dariusz Surel

Bialystok University of Technology, Poland ORCID 0000-0003-1174-5545

Corresponding author: e-mail: d.surel@doktoranci.pb.edu.pl

Katarzyna Halicka

Bialystok University of Technology, Poland ORCID 0000-0001-6370-8995

\section{INTRODUCTION}

In recent years, the ageing society trend has become increasingly more distinct. 2019 saw 703 million persons aged 65 years or over worldwide, and the number is projected to double to 1.5 billion in 2050
(United Nations, 2019). All world regions will see an increase in the size of their older populations between 2020 and 2050, and the share of the global population aged 65 years or over is expected to increase from 9.3 $\%$ in 2020 to $16 \%$ by 2050 . As in other European

Halicka, K., \& Surel, D. (2021). Gerontechnology - new opportunities in the service of older adults. Engineering Management in Production and Services, 13(3), 114-126. doi: 10.2478/emj-2021-0025 
countries and the rest of the world, the phenomenon of an ageing society is evident in Poland. In the first half of 2020, the population of Poland was over 38 million (38 354 173), of which over 7 million were aged 65 years and older (Central Statistics Office Poland, 2020). For comparison, in 2019, the number of older people (aged 65 and over) was less than 7 million (6 947 019) (Central Statistics Office Poland). The data show a growing number of older adults in Poland, and this trend may continue in the future.

The ageing phenomenon may have several causes. Based on Cursaru, the main factors of population ageing are declining fertility rates and increasing life expectancy, which was much lower in the 19th century (Cursaru, 2018). The ageing population can be considered a negative phenomenon due to greater strains on budgets for pensions, medical care or various benefits (Jarocka \& Wang, 2018). The ageing trend is also largely related to the improvement of living conditions and a wider and more developed healthcare system. Increasing numbers of older adults also want to take care of their physical and mental health, which directly translates into longer life.

The silver economy is worth mentioning in raising the issue of population ageing. The concept of the silver economy is defined as a considered part of the general economy that is relevant to the needs and demands of older adults (European Union Publications Office, 2018). Klimczuk (2016) defined the concept of the silver economy as a system based on adapting the production and distribution of products and services to older adults and, consequently, to all age groups. This ideal of an economic system originated in Japan, centred on the diverse needs of seniors (Klimczuk, 2011). Another definition of the silver economy proposed by Oxford Economics defines it as "the sum of all economic activity serving the needs of those aged 50 and over including both the products and services they purchase directly and the further economic activity this spending generates" (Oxford Economics). In the past, the silver market concept has also been used, defined as an industry modifying existing products to increase their usability to older consumers (Zimnoch, 2013). The concept of the silver economy seeks to look holistically at ageing and also the opportunities it presents, bearing on the future direction of a broad range of policies, such as those on the built environment, life-long learning, 50+ employment, and preventive healthcare (Bojanić \& Erceg, 2017). The European Commission also defines the silver economy as economic opportunities arising from the public and consumer expenditure related to population ageing and the specific needs of the population over 50 (European Commission, 2015).

While focusing on population ageing and the silver economy, gerontechnology has become a significant area of science. Based on international and national programmes or scientific research activities, the need for technological development has become widespread (Halicka, 2020). Nowadays, technologies are developing incredibly fast, and the ageing society necessitates the design of technologies dedicated to older adults who often need support in different areas of life. This demand can be met with the help of gerontechnology - a combination of gerontology and technology. Gerontology may be defined as a scientific study of ageing that examines the biological, psychological, sociological factors associated with old age and ageing (Brossoie, 2018). At the beginning of the development of gerontechnology, Bouma (1992) defined this area of science as a "study of technology and ageing for the improvement of the daily functioning of the older adults". Based on Rzeczynski (2009), this field focuses on the social and environmental aspects of older people. Another definition is that gerontechnology can help older adults identify and slow down the effects of age-related modifications of the neural and musculoskeletal systems (Sale, 2018). According to Boruta (2017), the growing caring needs of an ageing society cannot be met only with the increase in the number of carers; thus, technologies should be developed to assist older people. Also, gerontechnology officially became an academic field at the First International Congress on Gerontechnology, which was held in 1991 in Eindhoven, the Netherlands (Hsu \& Li Bai, 2016).

In the development of gerontechnology, research should focus on technologies improving the quality of life of older people. The related literature offers various studies on technologies supporting older adults. Halicka and Ejdys (2018) conducted a study on humanoid robots designed to provide care to older adults and the related attitude towards such technologies. Researchers from the USA studied the use and understanding of social communication technologies by older adults and their attitude towards this type of technology (Bixter et al., 2019). Older people may encounter problems with memory and memorising, so another study focused on memory notebooks and their usefulness (Dahmen et al., 2018). Over time and with the increasing ageing trends within the population, there is a need to conduct research on technologies that make life easier for older adults. Increasingly 
more advanced technologies emerge and must be carefully analysed, also assessing the users' approach to such technologies. The subject of gerontechnology is relatively well known globally yet might be somewhat new for some people in Poland. As a niche topic in Poland and worldwide, gerontechnology requires more research on technologies improving the quality of life of older people. In the aim to develop the gerontechnology sector in Poland, opinions, approaches and needs related to gerontechnology should be recognised.

\section{LITERATURE REVIEW}

There are many different types of gerontechnologies, ranging from modern mobile wheelchairs through systems monitoring houses and flats, ending with various health applications or robots supporting the functioning of older adults. These are just some examples of the technologies helping older people in their everyday functioning. Different technologies may need to be separated into individual categories or groups. There is no single universal, generally accepted classification of gerontechnologies; however, the related literature proposes several classifications. Based on a detailed analysis of the literature, this article proposes another classification of gerontechnologies into nine main groups, i.e., Health, Education, Interpersonal Communication, Safety, Mobility, Care, Leisure, Housing, and Digital Accessibility (Halicka \& Surel, 2020).

The first group of technologies is related to the broadly understood health of older people. This group includes all technologies involved in the care for and monitoring of human health, also including telehealth and telemedicine technologies. A good example of technology that falls into the health category is the Amulet Device (Batsis et al., 2018), which looks like a smartwatch with dimensions of $4 \mathrm{~cm} 2$, a slider with a black and white screen, and two buttons. The device can run applications tracking and monitoring health, i.e., activity, stress, strength, steps. The collected data can be stored on a micro-SD card or transmitted over Bluetooth to a tablet or smartphone. Another great example of such technology is an electronic pillbox (eMMD) (Tellier et al., 2020). The device consists of a connector and 28 compartments covered with a membrane that detects motion. Each compartment can hold several pills. When the time comes to take medicines, eMMD sends a sound alert and switches a green light indicator on the compart- ment with pills to be taken. This technology can help older people by reminding them to take medicines at the right time.

Another group of gerontechnologies are related to education. With the growing popularity of third age universities, other education solutions are being created for older adults, such as applications for tablets/smartphones for learning, e.g., foreign languages. Digital learning games make learning for older people accessible and enjoyable. A good example of such a game is LEAGE. The game aims to help older people improve their competencies by practising and expanding knowledge on topics of history, geography, nutrition, health problems by motivating exercises and memory training (Nap et al., 2014). This game is available in two versions (one played by a TV remote control on a Set-Top Box, and the other using a 3D Microsoft Kinect sensor), helping older people to learn different knowledge in a very interesting and active way.

Interpersonal Communication is the third group of technologies supporting older adults facing issues related to communication with others. Thus, this group of technologies is mainly based on facilitating interpersonal communication between older adults, their families and friends. To make communication easier, simplified smartphones are offered, e.g., with larger keys and screens (Assisted Living Today). Video calls may be a great convenience for older adults making it possible to see members of their families. Various special devices are available, making communication easier and user-friendlier for older adults.

Safety is of the utmost importance to the functioning of older people; therefore, the fourth group of gerontechnologies concerns this type of solution. E.g., these technologies can inform families that something may have happened to their older adult. A technology that fits well into this group is the smartphone application SteadyTM (Hsieh, Fanning \& Sosnoff, 2019), which was developed specifically for older adults, considering their unique usability preferences and needs (Bernard, Liao \& Mills, 2001). The application consists of two components that compute a fall risk score (Hsieh et al., 2018), where the first component is a 13-item questionnaire of health history (age, gender, number of falls in the last year, perceived balance confidence). The second component is a progressive postural stability test, which guides the user through five balance tasks of progressive difficulty. This information, together with data from the health history questionnaire, is entered 
into a weighted algorithm to produce a score and classification of a degree of the fall risk (very low, low, moderate, high and very high).

Mobility issues become more problematic with age as well. Older people may have difficulty climbing stairs; some use various aids to help with movement. The 5th group of gerontechnologies concerns the broad subject of mobility. Advancing wheelchair technologies are available to people with serious legs and back problems. The ordinary wheelchairs controlled and driven by muscle power (either by the wheelchair user or a helper) are replaced by technologies controlled using a joystick. This solution requires a wheelchair user to have a fit hand and may be inaccessible to paralysed people. Rapidly developing technologies offer other types of control, i.e., by eye or mouth movement. Another good example of mobility technologies is the SMILING Shoe, which is a complex mechatronic system requiring the interaction of mechanical components, human activity and various sensor data. The shoe is worn on a standard shoe, and the user has to react to changes of shoe inclinations to keep balance while walking and completing different, specific tasks (Simsik, 2012). This device might be very helpful in the rehabilitation of older adults.

Another very important group of gerontechnologies focuses on caring for seniors, which is an extremely important and time-consuming activity. Seniors are often unable to cope with all everyday life tasks, thus requiring assistance. As family members do not always have enough time, other solutions must be found. Robots can bring a great change in the relationship between humans and technologies, making the issue of older people's trust in future technologies especially significant (Ejdys, 2018). Nowadays, greater emphasis is placed on the development of artificial intelligence and various types of robots. Therefore, scientists and engineers focus on building and developing robots to take care of older adults. Wieczorek (2016) reviewed two types of robots used in the care for older adults: social robots communicating with the user and assistive robots. Halicka (2019) studied how robots were evaluated against various criteria and whether the age and gender of respondents influenced the evaluation of the technology. Robots caring for older adults can be a revolutionary solution. It can put older adults at the ease of knowing that help is always available and relieve younger family members of additional duties. Also, robots could take over a large part of duties currently performed by professionals (e.g., nurses), such as helping older adults to move around. A good example of such a robot is Robear. This nursing robot can help older people by lifting them from a bed to a wheelchair, provide support while standing (if required) (RoboticsBIZ). Another great example is a robot named Care-O-bot (Care-O-bot), which can also help older adults in their daily lives. It is intended to be an affordable care option with six configurable models depending on the available budget and needs (RoboticsBIZ).

It is important to provide adequate entertainment for older people who have free time. Dynamically developing technologies also focus on the leisure of older adults. This type of technology is covered by the seventh group of gerontechnologies in the classification.

Home safety is yet another important topic for older adults. This type of technology is covered by the group of gerontechnologies called "Housing" and includes various monitoring systems, hazard detection devices and technologies that automatically notify relevant emergency services or family members. Also, the group includes various types of devices and solutions that make it easier for seniors to function independently in their homes.

The last group of gerontechnologies is named "Digital Accessibility". Older people may want to use technologies but feel reluctant because of the fear they would be too advanced or difficult to learn. Older people may encounter considerable problems with the use of smartphones or computers. As these devices are essential for communication, messaging, and information, such as the weather, engineers create special devices that are easy to use for older adults, ensuring easy access to such technologies.

To be able to market and develop the abovementioned groups of technologies improving the quality of life of older people, it is necessary to assess these technologies against various criteria, e.g., innovation, usability, functionality, demand for a particular class of technology, ease of use or ethics. It is also necessary to identify the most desirable gerontechnology groups for current and future users. So far, both globally and in Poland, no such research has been conducted. The existing research only concerns the degree of acceptance of the technologies that improve the quality of life for older people. The opinions of future or potential users have not been considered either. The literature also presents research on one arbitrarily chosen gerontechnology. No studies were conducted to assess different classes of gerontechnologies. 
The analysis and assessment provided in this article were made considering different criteria of the nine above-mentioned classes of gerontechnologies. The literature studies and exploratory research conducted so far allow the following research questions to be formulated: (1) Which of the nine gerontechnology groups is most desired by current and future users? (2) What are the individual assessments of future and current users of the most desirable gerontechnology depending on the type of criteria? (3) For which criterion has the selected, most desirable group of gerontechnologies been rated the highest?

\section{RESEARCH METHODS}

A survey was carried out in early 2020 to assess the nine gerontechnology groups considering various criteria and to identify the most desirable gerontechnology for users. The survey sample was representative and amounted to 1152 Polish citizens over 40 years of age. The survey was conducted using CATI (Computer-Assisted Telephone Interview) and CAWI (Computer-Assisted Web Interview) methods.

In the sample structure, $26.3 \%$ (303 people) were aged 40-49, $28.6 \%$ (329 people) were aged 50-59 and $45.1 \%$ (520 people) were over 60. Men comprised $45.7 \%$ (527 people) of the sample and $54.3 \%$ (625 people) were women.

The survey was conducted among the inhabitants of Poland. The smallest group of respondents came from cities with $150000-250000$ inhabitants $(9.8 \%$, 113 people) and cities with up to 20 thousand inhabitants (11.1\%, 128 people). The largest groups of respondents came from cities with over 250000 inhabitants (26.5\%, 305 people) and from cities with 50000 - 150000 inhabitants (19.2\%, 221 people).

The vast majority of respondents had secondary education ( $45.8 \%$ ), some (9.5\%) had only primary education, over $25 \%$ of the respondents had a higher education degree. The rest of the respondents (19\%) had vocational education.

\section{RESEARCH RESULTS}

The respondents were asked which of the nine gerontechnology groups were the most desired by current and future users. The most important group of gerontechnologies was related to the health (G1) and safety of older adults. The third and fourth places were given to the "Care" group and the "Interpersonal
Communication" group. The following ranks were given to "Mobility", "Education" and "Leisure". The least important groups were "Housing" and "Digital Accessibility".

As the most important gerontechnology group was related to health, it assessed in detail, considering various criteria. Initially, on the basis of the literature review, the following criteria were identified: innovation, demand, usability, functionality, ease of use, risk related to the use of a given gerontechnology, and social and ethical aspects. The criteria were developed in the form of questions. 30 criteria were identified with six questions related to the functionality of the technology (TF1-TF6), five - to technological innovation (TI1-TI5) and demand for the technology (TD1-TD5), four - to social and ethical aspects (SEC1-SEC4), and four - to the risk of using the technology (TUR1-TUR4). Lastly, three criteria were associated with the usability of the technology (TU1TU3) and ease of use (TEU1-TEU3). The list of criteria used in the assessment of gerontechnologies in Poland is presented in Table 1.

The respondents assessed the G1 using each criterion. They had to determine to what extent the use of G1 would contribute to the fulfilment of a criterion. A 9-point score was used for the evaluation, where one meant "to a very small extent", and nine meant "very much". E.g., choosing one for the TI1 criterion meant that the technologies from the G1 group were considered low innovation. On the other hand, choosing nine for the TI2 criterion meant that the application of the G1 technology would greatly improve the quality of the existing care system.

The G1 was initially assessed against the innovation criteria. Most of the respondents (over $55 \%$ ) considered that applying this group of technologies to care for older adults was, to a large extent, an innovative solution in demand (TI1). Almost $60 \%$ of the respondents believed that the application of this group of technologies to care for older adults would greatly improve the quality of the existing care system (TI2). Less than half of the respondents stated that the use of this group of technologies to care for older adults was, to a large extent, a breakthrough solution globally (TI3), and over $57 \%$ of the respondents stated that it was a breakthrough solution for Poland (TI4). The vast majority of the respondents stated that this group of technologies could significantly improve the quality of life of older people, and only $7.7 \%$ of the respondents believed that this group of technologies could do little to improve the quality of life of older people (TI5). Detailed data on the technology 
Tab. 1. Catalogue of group assessment criteria

\begin{tabular}{|c|c|}
\hline ACRONYM & NAME OF CRITERION \\
\hline \multicolumn{2}{|r|}{ Technology innovation } \\
\hline TI1 & To what extent is the use of this group of technologies for the care of older adults an innovative solution in demand? \\
\hline $\mathrm{T} 12$ & $\begin{array}{c}\text { To what extent will the application of this group of technologies for the care for older adults significantly improve the } \\
\text { quality of the existing care system? }\end{array}$ \\
\hline $\mathrm{TI} 3$ & $\begin{array}{l}\text { To what extent is the use of this group of technologies for the care of older adults a breakthrough solution in the } \\
\text { world? }\end{array}$ \\
\hline TI4 & To what extent is the use of this group of technologies for the care of older adults a breakthrough solution in Poland? \\
\hline $\mathrm{T} 15$ & $\begin{array}{c}\text { To what extent can the use of this group of technologies for the care of older adults significantly improve the quality } \\
\text { of life of older adults? }\end{array}$ \\
\hline \multicolumn{2}{|r|}{ Technology demand } \\
\hline TD1 & To what extent is there a demand from older people for technologies from this group? \\
\hline TD2 & To what extent is there a demand for this technology from family members for technologies from this group? \\
\hline TD3 & To what extent is the global demand for technologies from this group is related to fashion? \\
\hline TD4 & To what extent will the use of technologies from this group require no new specialised knowledge? \\
\hline TD5 & To what extent will this group of technologies be important for everyday life? \\
\hline \multicolumn{2}{|r|}{ Social and ethical criteria } \\
\hline SEC1 & $\begin{array}{c}\text { To what extent will the widespread use of this technology in the care of older adults bring measurable social ben- } \\
\text { efits? }\end{array}$ \\
\hline SEC2 & To what extent will the widespread use of this technology in the care of older adults create new jobs? \\
\hline SEC3 & $\begin{array}{l}\text { To what extent will the widespread use of this technology in the care of older adults bring measurable benefits for } \\
\text { human health and quality of life? }\end{array}$ \\
\hline SEC4 & To what extent can the widespread use of technologies in the care of older adults be a source of social problems? \\
\hline \multicolumn{2}{|r|}{ Technology usability } \\
\hline TU1 & To what extent will the use of technologies from this group improve the quality of care services for older adults? \\
\hline TU2 & To what extent will the use of this technology for the care of older adults improve their safety? \\
\hline TU3 & $\begin{array}{c}\text { To what extent will the use of this technology for the care of older adults contribute to spending time pleasantly and } \\
\text { enjoyably? }\end{array}$ \\
\hline \multicolumn{2}{|r|}{ Technology functionality } \\
\hline TF1 & To what extent will the technologies in this group mean that older adults have to do no heavy work? \\
\hline TF2 & To what extent will the functionality of the technologies in this group enable interaction? \\
\hline TF3 & $\begin{array}{c}\text { To what extent will the functionality of the technologies in this group enable older adults to inform their loved ones } \\
\text { about their health? }\end{array}$ \\
\hline TF4 & $\begin{array}{c}\text { To what extent will the functionality of the technologies in this group make it possible to call for help for older } \\
\text { adults? }\end{array}$ \\
\hline TF5 & $\begin{array}{l}\text { To what extent will the functionality of this group of technologies make the movement of older people easier and } \\
\text { more efficient? }\end{array}$ \\
\hline TF6 & To what extent will the use of the technologies from this group improve the everyday life of older adults? \\
\hline \multicolumn{2}{|r|}{ Technology ease of use } \\
\hline TEU1 & To what extent does the use of the technologies from this group require breaking down mental barriers? \\
\hline TEU2 & To what extent should the use of this technology be easy and intuitive? \\
\hline TEU3 & To what extent would you find it difficult to learn to use this technology? \\
\hline \multicolumn{2}{|r|}{ Technology use risk } \\
\hline TUR1 & To what extent can the use of this group of technologies for the care of older adults be a source of danger? \\
\hline TUR2 & $\begin{array}{l}\text { To what extent can the use of this group of technologies for the care of older adults expose users to a loss of health } \\
\text { or life? }\end{array}$ \\
\hline TUR3 & To what extent can the technologies in this group pose a threat to human relationships? \\
\hline TUR4 & To what extent would you be able to trust the technologies in this group? \\
\hline
\end{tabular}


innovation criterion for the "Health" group is presented in Fig. 1.

Another considered criterion was "Technology Demand". More than half of the respondents stated a significant demand for technologies from this group for older adults (TD1), and almost $61 \%$ of the respondents believed in a significant demand for these technologies from family members (TD2). More than $43 \%$ of the respondents believed that the global demand for technologies in this group was to a medium extent related to fashion, and almost $33 \%$ did not believe that this phenomenon was temporary (TD3). More than $20 \%$ of the respondents said that the use of these technologies would require older adults to acquire specialised knowledge (TD4). The majority of the respondents said the appearance of the technologies would be important for using them daily (TD5). Detailed data on the criterion of demand for technologies for the "Health" group are presented in Fig. 2.
Social and ethical criteria were examined next (Fig. 3). The vast majority of respondents expressed that using technologies from this group would bring measurable social benefits. Almost $44 \%$ of the respondents claimed that using this group of technologies would contribute to the creation of new jobs to an average extent (SEC2). $57 \%$ of the respondents stated that using technologies from this group would bring measurable benefits for human health and the quality of human life (SEC3). Over $22 \%$ of the respondents said that the widespread use of these technologies might be a minor source of social problems (SEC4).

The respondents were asked to rate the group of technologies in terms of usability (Fig. 4). The vast majority of respondents agree that technologies from this group would improve the quality of care services for older adults (TU1). Over $58 \%$ of the respondents claimed that using technologies from this group would improve the safety of older people (TU2). Less

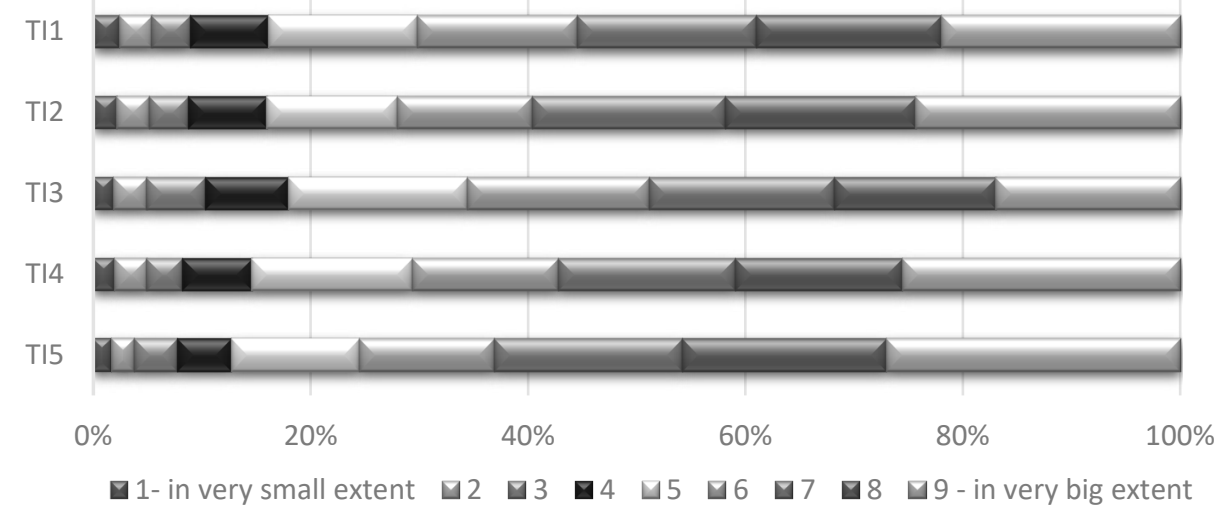

Fig. 1. "Health" gerontechnology group assessment in terms of the Technology Innovation criteria

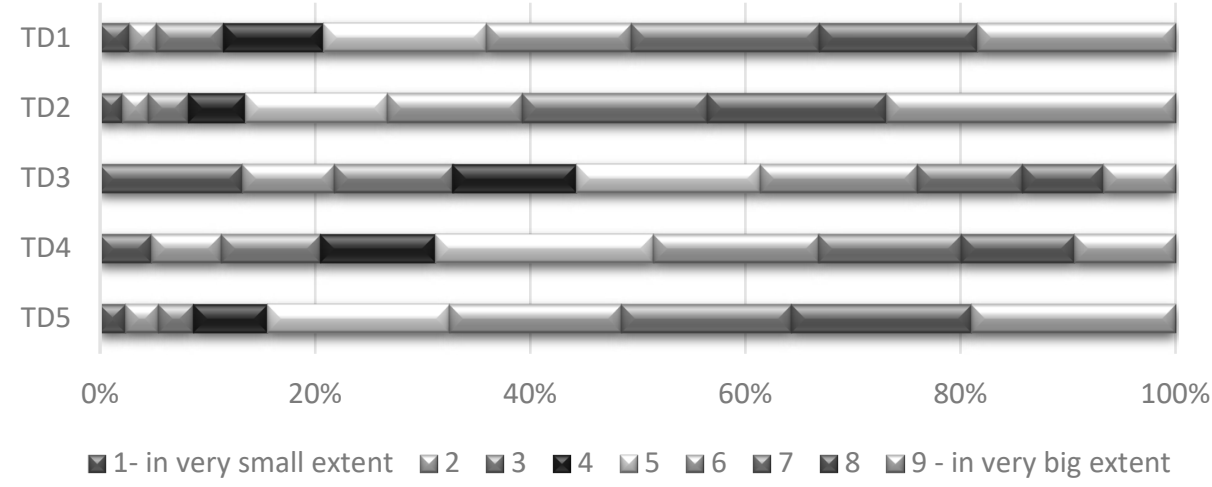

Fig. 2. "Health" gerontechnology group assessment in terms of the Technology Demand criteria 


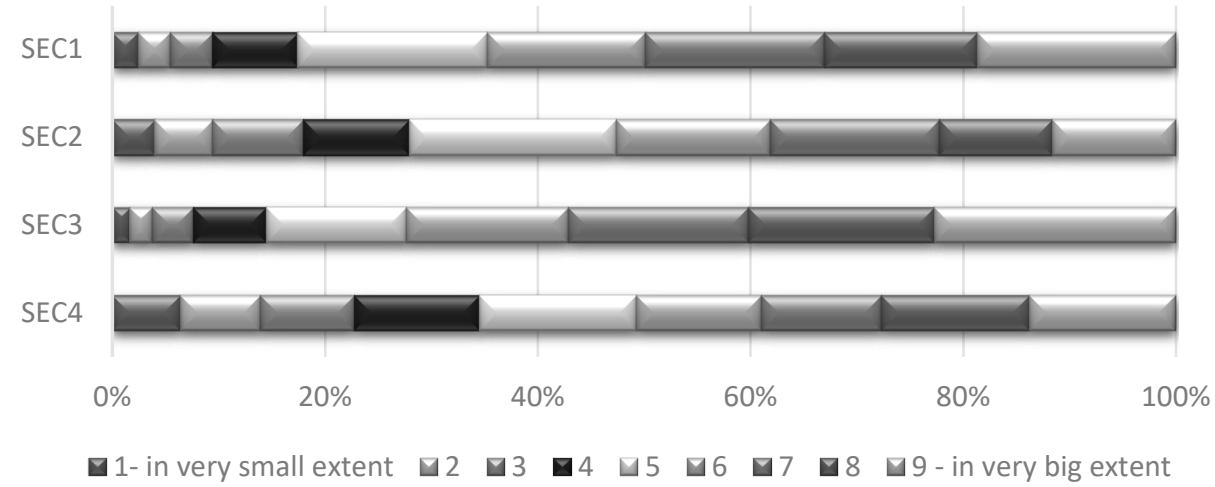

Fig. 3. "Health" gerontechnology group assessment in terms of the Social and Ethical criteria

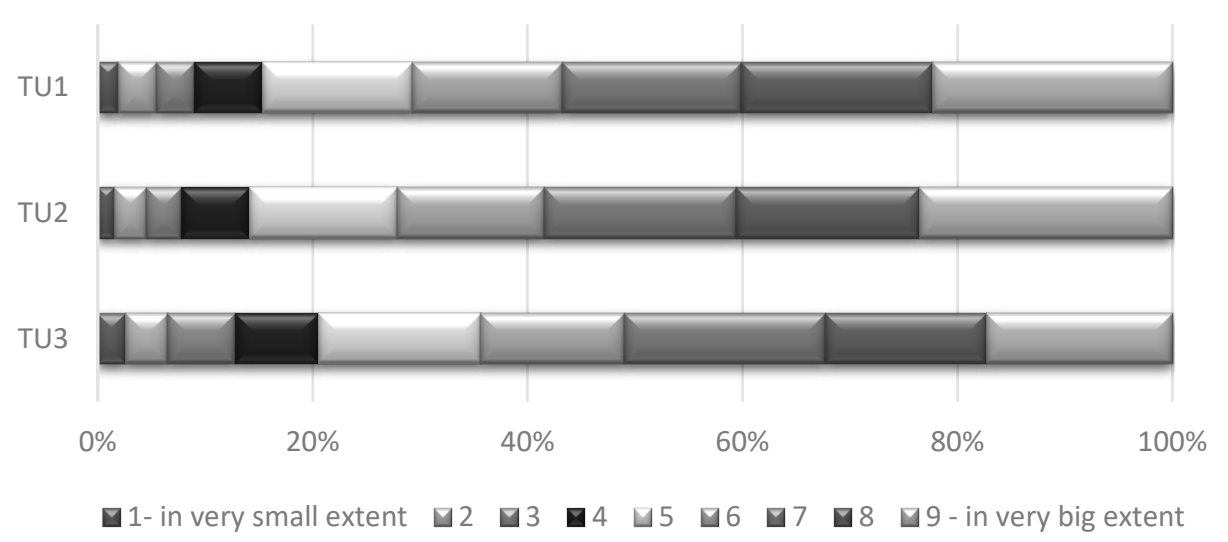

Fig. 4. "Health" gerontechnology group assessment in terms of the Technology Usability criteria

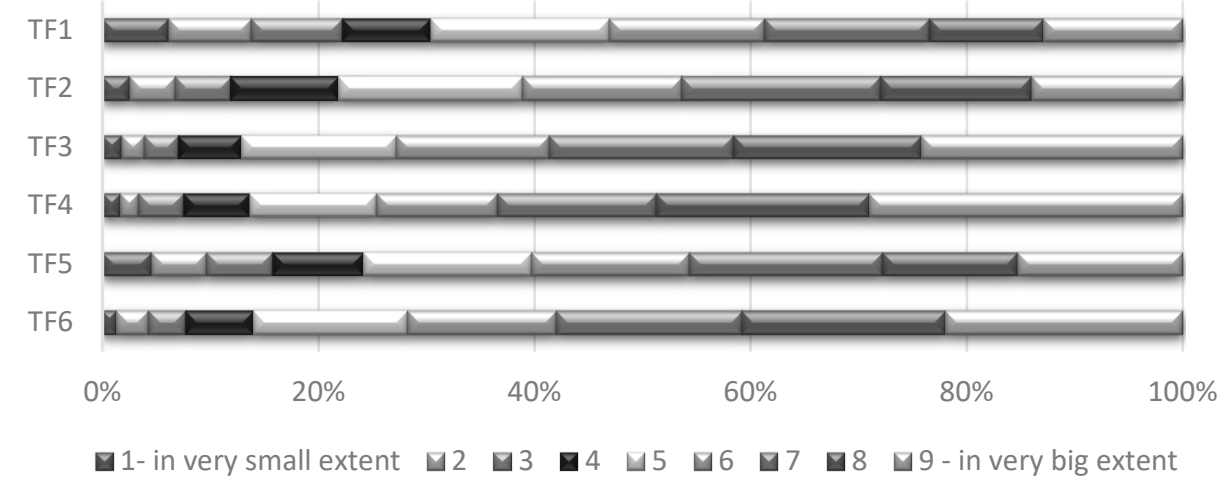

Fig. 5. "Health" gerontechnology group assessment in terms of the Technology Functionality criteria

than $13 \%$ of the respondents stated that using technologies from this group would have little contribution to time spent pleasantly by older adults (TU3).

The next step was to evaluate the groups of technologies for functionality (Fig. 5). Almost $39 \%$ of the respondents claimed that primarily due to technologies from this group, older adults would no longer have to engage in difficult activities (TF1). The vast majority of the respondents (88.2\%) agreed that the functionalities of technologies from this group would 
make interactions possible (TF2). Over $58 \%$ of the respondents answered that the functionality of the technologies from this group would make it possible, to a large extent, to inform loved ones about the health of older adults (TF3). Only $7.6 \%$ of the respondents claimed that these technologies would hardly make it possible to call help for older adults (TF4). A large proportion of the respondents ( $45.7 \%$ ) replied that the technologies from this group would make the movement of older adults much easier and more efficient (TF5). Over $90 \%$ of the respondents agreed with the statement that these technologies would improve the daily functioning of older people (TF6).

The respondents also rated health-related technologies for ease of use (Fig. 6). Over $41 \%$ of the respondents answered that using technologies from this group to an average extent would require breaking mental barriers (TEU1). The vast majority of the respondents (54.5\%) agreed that using the technologies from this group should be easy and intuitive (TEU2). Over $40 \%$ of the respondents answered that learning to use the technologies from this group would be a little difficult for them (TEU3).

The last criterion analysed was related to the risk of using the technology (Fig. 7). Nearly $45 \%$ of the respondents stated that using the technologies from this group might largely be a source of risks (TUR1). Less than $50 \%$ of the respondents considered that using these technologies for older adults may largely expose users to a loss of health or life (TUR2). More than $16 \%$ of the respondents answered that the technologies from this group, to a small extent, might pose a threat to human relations (TUR3). $47 \%$ of the

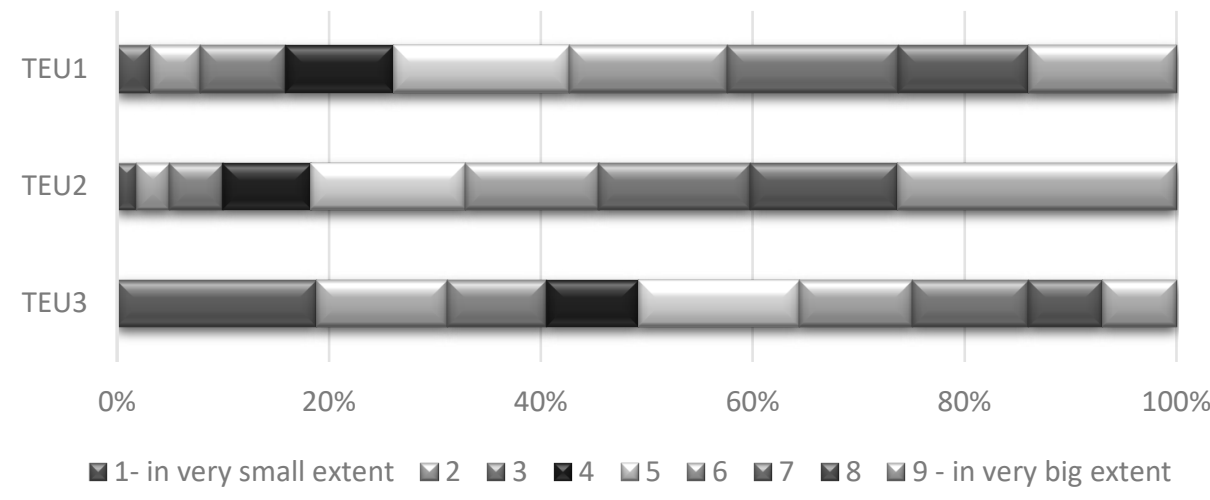

Fig. 6. "Health" gerontechnology group assessment in terms of the Technology Ease of Use criteria

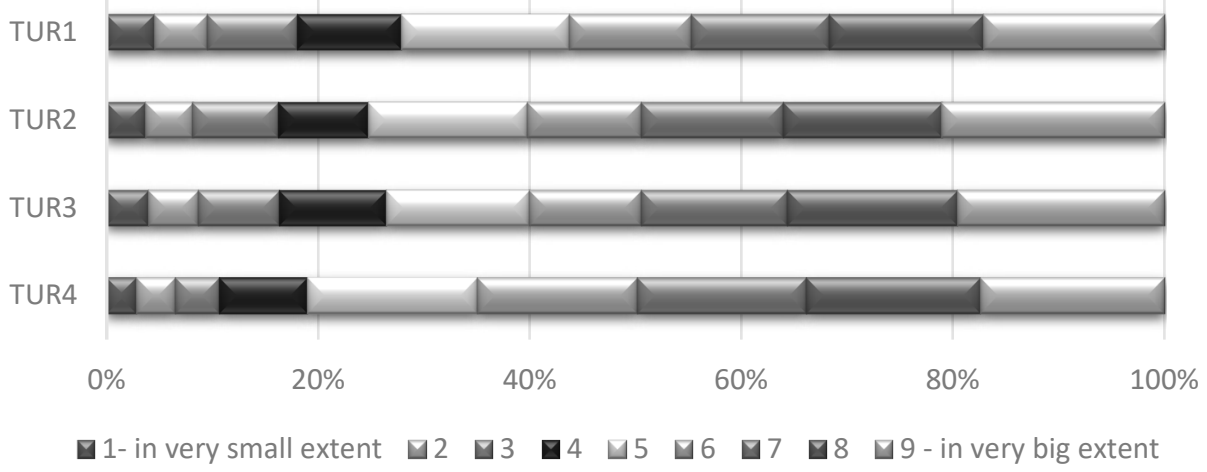

Fig. 7. "Health" gerontechnology group assessment in terms of the Technology Use Risk criteria 
respondents stated that they would be able to trust this group of technologies to a medium degree.

\section{DISCUSSION OF THE RESULTS}

A summary of average ratings given by the gerontechnology respondents from the G1 group (health) for each criterion is presented in Fig. 8. The figure shows arithmetic averages of the respondents' marks for each criterion. E.g., the opinion average for the gerontechnology respondents from the health group regarding the use risk was 6.10, and for usability -6.49 . The maximum value of technology evaluation was nine, and the minimum value was one. Based on the figure, G1 was ranked the highest for innovation (6.60) and lowest for ease of use (5.61).

A more detailed list of the average assessments for G1 gerontechnology depending on a specific criterion is presented in Table 2. Based on the data, G1 technologies were rated the lowest for the TEU3 criterion, which means that learning to use technologies from this group would not be difficult. On the other hand, the highest assessments were given to technologies improving the quality of life for older people in terms of the TF4 criterion, which shows the importance of the functionality to call for help by an older person. Considering innovation (TI), G1 technologies were rated the highest for the criterion TI5 (significantly improve the quality of life of older adults) and the lowest for the criterion TI3 (a breakthrough solution globally). In terms of demand, G1 was rated the highest for TD2 (demand for technology by family members supporting older adults) and the lowest for TD3 (global demand for technologies supporting older adults related to fashion). This shows a very high demand for technologies from this group, while the global demand for technologies from this group is not related to fashion. In terms of functionality, G1 has the highest rating for TF4 (making it possible to call for help for older adults) and the lowest for TF1. Therefore, according to the respondents, technologies from this group would be useful to call for help for

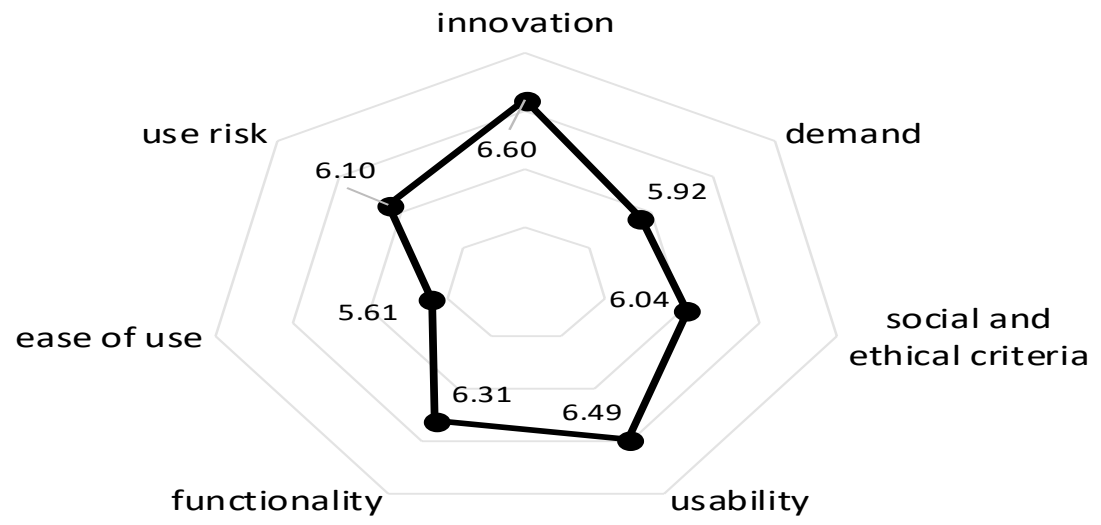

Fig. 8. Average of gerontechnology assessments of the Health group in terms of different groups of criteria

Tab. 2. Average assessment of gerontechnology G1 depending on each of the identified criteria

\begin{tabular}{|l|l|l|l|l|l|}
\hline $\begin{array}{c}\text { ACRONYM OF CRI- } \\
\text { TERION }\end{array}$ & \multicolumn{1}{|c|}{$\begin{array}{c}\text { AVERAGE ASSESS- } \\
\text { MENT }\end{array}$} & $\begin{array}{c}\text { ACRONYM OF CRI- } \\
\text { TERION }\end{array}$ & $\begin{array}{c}\text { AVERAGE ASSESS- } \\
\text { MENT }\end{array}$ & $\begin{array}{c}\text { ACRONYM OF CRI- } \\
\text { TERION }\end{array}$ & $\begin{array}{c}\text { AVERAGE ASSESS- } \\
\text { MENT }\end{array}$ \\
\hline TI1 & 6.54 & SEC1 & 6.32 & TEU1 & 5.87 \\
\hline TI2 & 6.66 & SEC2 & 5.65 & TEU2 & 6.53 \\
\hline TI3 & 6.28 & SEC3 & 6.65 & TEU3 & $\mathbf{4 . 4 2}$ \\
\hline TI4 & 6.65 & SEC4 & 5.53 & TUR1 & 5.90 \\
\hline TI5 & 6.86 & TF1 & 5.56 & TUR2 & 6.14 \\
\hline TD1 & 6.26 & TF2 & 6.06 & TUR3 & 6.09 \\
\hline TD2 & 6.76 & TF3 & 6.72 & TUR4 & 6.27 \\
\hline TD3 & 4.71 & TF4 & 6.90 & TU2 & 6.58 \\
\hline TD4 & 5.43 & TF5 & TF6 & 6.95 & TU3 \\
\hline TD5 & 6.42 & & & 6.67 \\
\hline
\end{tabular}


older adults. Analysing the social and ethical aspects, G1 was rated the highest in terms of the SEC3 criterion, which means that technologies from this group would bring measurable benefits for human health and the quality of life. In terms of socio-ethical aspects, technologies from this group received the lowest ranking for the SEC4 criterion, which means that technologies from this group should not be the source of social problems.

\section{CONCLUSIONS}

The article assesses various technologies that improve the quality of life of older people. The research mainly aimed to find answers to the following questions: (1) What is the ranking of gerontechnology groups, and which of the nine gerontechnology groups is most desired by current and future users? (2) What are the individual assessments of future and current users of the most desirable gerontechnology depending on the type of criterion? (3) For which criterion has the selected, most desirable group of gerontechnology been rated the highest?

The conducted research helped to determine that technologies improving the quality of life of older adult related to health were rated the highest (G1 Health Group - the first place in the ranking). Among the most popular technologies in this group were a video chat with a doctor, mHealth mobile applications, an electronic medicine dispenser, and a telemedicine wristband.

Technologies from this group were rated the highest for innovation (the mean score of 6.60 on a scale from 1 to 9), usability (the mean score of 6.49 on a scale from 1 to 9) and functionality (6.31). The lowest rating was given to this group in terms of ease of use (the mean score of 5.61 on a scale from 1 to 9).

The results demonstrate that the respondents believed learning to use health-related technologies should not be a problem (the lowest obtained mean score was 4.42). The highest rating was given to these technologies in terms of functionality, allowing to call for help for an older adult (the highest average score obtained was 6.90).

The second place in the ranking was given to technologies improving the quality of life of older people in the G4 group - safety, and the third place in G6 - care. The lowest rating was given to gerontechnologies from the G9 group - digital accessibility.
In the future, the authors intend to extend the research to a larger sample and other countries (e.g., the European Union countries) and include other technology assessment criteria, such as Technological Readiness Levels (TRL) or Life Cycle Analysis (S-LCA). In addition, the plan is to use MCGDM (Multiple Criteria Group Decision Making) methods such as TOPIS, SAW, and to research the projection of gerontechnology development in the future, in the perspective of 20-30 years. This will involve the application of foresight methods, which are widely used for the creation of a long-term vision for the development of countries, cities, technologies, enterprises and various institutions (Nazarko et al., 2017; Ejdys et al., 2019; Szpilko, 2020; Nazarko et al., 2019).

\section{ACKNOWLEDGEMENTS}

This research was funded by the Ministry of Science and Higher Education, grant number W/WIZ/1/2019 and W/WIZ/9/2020.

The publication of the article for 11th International Conference on Engineering, Project, and Production Management - EPPM2021 was financed in the framework of the contract no. DNK/ SN/465770/2020 by the Ministry of Science and Higher Education within the "Excellent Science" programme.

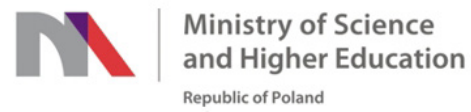

\section{LITERATURE}

Assisted Living. Top 25 smartphones for Seniors. Retrieved from https://assistedlivingtoday.com/blog/bestsmartphones-for-seniors/

Batsis J. A., Zagaria, A., Kotz, D. F., Bartels, S. J., Boateng, G. G., Proctor, P. O., Halter, R. J., \& Carpenter-Song, E. A. (2018). Usability evaluation for the Amulet Wearable Device in rural older adults with obesity. Gerontechnology, 17(3), 151-159. doi: 10.4017/ gt.2018.17.3.003.00

Bernard, M., Liao, C. H., \& Mills, M. (2001). The effects of font type and size on the legibility and reading time of online text by older adults. Paper presented at the CHI'01 extended abstracts on Human factors in computing systems.

Bixter, M. T., Blocker, K. A., Mitzner, T. L., Prakash, A., \& Rogers, W. A. (2019). Understanding the use and non-use of social communication technologies by older adults: A qualitative test and extension of the 
UTAUT model, Gerontechnology, 18(2), 70-88. doi: 10.4017/gt.2019.18.2.002.00

Bojanić, I. B., \& Erceg, A. (2017). Silver Economy: Demographic change and economic opportunity, Economic Development, Technological Change and Growth. Interdisciplinary Management Research Conference XIII, Croatia, Opatija.

Boruta, M. (2017). Gerontechnologia jako narzędzie w procesie zaspokajania potrzeb mieszkaniowych seniorów [Gerontechnology in providing for the housing needs of the elderly]. Progress in Economic Sciences, 4, 25-36. doi: 10.14595/PES/04/002

Bouma, H. (1992). Gerontechnology: Making technology relevant for the elderly. In H. Bouma \& J. A. M. Graafmans (Eds.), Gerontechnology (pp. 1-5). Amsterdam, Netherlands: IOS Press.

Brossoie, N. (2018). Social Gerontology, Chapter 2. Jones and Bartlett Publishers.

Care-O-bot. Retrieved from https://www.care-o-bot.de/en/ care-o-bot-4.html

Central Statistic Office Poland. (2020). Ludność. Stan i struktura ludności oraz ruch naturalny w przekroju terytorialnym w 2020 r. [Population. Population status and structure and natural movement in territorial section in 2020]. Retrieved from https://stat.gov.pl/ obszary-tematyczne/ludnosc/ludnosc/ludnosc-stan-istruktura-ludnosci-oraz-ruch-naturalny-w-przekroju-terytorialnym-stan-w-dniu-30-06-2020,6,28.html

Central Statistics Office Poland. (2020). Ludność. Stan i struktura ludności oraz ruch naturalny w przekroju terytorialnym [Population. Population status and structure and natural movement in territorial section]. Retrieved from https://stat.gov.pl/obszary-tematyczne/ ludnosc/ludnosc/ludnosc-stan-i-struktura-ludnoscioraz-ruch-naturalny-w-przekroju-terytorialnymstan-w-dniu-31-12-2019,6,27.html

Cursaru, A. (2018). Main Causes of Population Aging and its Consequences on the provision of Healthcare. ECON322.

Dahmen, J., Minor, B., Cook, D., Vo, T., \& Schmitter-Edgecombe, M. (2018). Smart home-driven digital memory notebook support of activity self-management for older adults. Gerontechnology, 17(2), 113-125. doi: 10.4017/gt.2018.17.2.005.00

Ejdys, J. (2018). Building technology trust in ICT application at a University. International Journal of Emerging Markets, 13(5), 980-997. doi: 10.1108/IJoEM-07-2017-0234

Ejdys, J., \& Halicka, K. (2018). Sustainable Adaptation of New Technology - The Case of Humanoids Used for the Care of Older Adults. Sustainability, 10(10), 3770. doi: 10.3390/su10103770

Ejdys, J., Gudanowska, A., Halicka, K., Kononiuk, A., Magruk, A., Nazarko, J., Nazarko, Ł., Szpilko, D., \& Widelska, U. (2019). Foresight in Higher Education Institutions: Evidence from Poland. Foresight and STI Governance, 13, 77-89. doi: 10.17323/25002597.2019.1.77.89

European Commission. (2015). Growing the European Silver Economy - Background paper. Retrieved from http://ec.europa.eu/research/innovation-union/pdf/ active-healthy-ageing/ silvereco.pdf
European Union Publications Office. (2018). The Silver Economy: Final Report 2018, Retrieved from https:// op.europa.eu/pl/publication-detail/-/publication/ a9efa929-3ec7-11e8-b5fe-01aa75ed71a1

Halicka, K. (2019). Gerontechnology - the assessment of one selected technology improving the quality of life of older adults. Engineering Management in Production and Services, 11(2), 43-51. doi: 10.2478/emj2019-0010

Halicka, K. (2020). Technology Selection Using the TOPSIS Method. Foresight and STI Governance, 14(1), 85-96. doi: 10.17323/2500-2597.2020.1.85.96

Halicka, K., \& Surel, D. (2020). Evaluation and Selection of Technologies Improving the Quality of Life of Older People, European. Research Studies Journal, 23(2), 592-611. doi: 10.35808/ersj/1611

Hsieh, K. L., Fanning, J. T., \& Sosnoff, J. J. (2019). A smartphone fall risk application is valid and reliable in older adults during real-world testing. Gerontechnology, 18(1), 29-35. doi: 10.4017/gt.2019.18.1.003.00

Hsieh, K. L., Fanning, J. T., Rogers, W. A., Wood, T. A., \& Sosnoff, J. J. (2018). A fall risk mHealth app for older adults: Development and usability study. JMIR Aging, 1(2), e11569. doi: 10.2196/11569

Hsu, Y., \& Li Bai, D. (2016). The Future of Gerontechnology: Proposals from the new editor-in-chief. Gerontechnology, 15(3), 125-129.

Jarocka, M., \& Wang, H. (2018). Definition and classification criteria of logistics services for elderly. Engineering Management in Production and Services, 10(4), 65-75.

Klimczuk, A. (2011). Transfer technologii w kształtowaniu srebrnej gospodarki [Technology transfer in shaping the silver economy]. In M. Grzybowski (Ed.), Transfer wiedzy w ekonomii i zarzadzaniu [Knowledge transfer in economics and management], (pp. 57-75). Gdynia, Poland: Wydawnictwo Uczelniane Akademii Morskiej w Gdyni.

Klimczuk, A. (2016). Modele srebrnej gospodarki w UE $\mathrm{w}$ ujęciu porównawczym. Próba wprowadzenia do dyskusji [Models of the silver economy in the EU in a comparative approach. An attempt to introduce you to the discussion]. Problemy Zarządzania, 14(2), 4159.

Nap, H. H., Diaz-Orueta, U., González, M. F., Lozar-Manfreda, K., Facal, D., Dolničar, V., Oyarzun, D., Ranga, M. M., \& de Schutter, B. (2014). Older people's perceptions and experiences of a digital learning game. Gerontechnology, 13(3), 322-331. doi: 10.4017/ gt.2015.13.3.002.00

Nazarko, J., Ejdys, J., Halicka, K., Nazarko, Ł., Kononiuk A., \& Olszewska, A. (2017). Structural Analysis as an Instrument for Identification of Critical Drivers of Technology Development. Procedia Engineering, 182, 504-509. doi: 10.1016/j.proeng.2017.03.137

Nazarko, Ł., \& Melnikas, B. (2019). Responsible Research and Innovation in Engineering and Technology Management: Concept, Metrics and Assessment. IEEE Technology \& Engineering Management Conference (TEMSCON). Retrieved from https://ieeexplore.ieee. org/document/8813596

Oxford Economics. (2013). The Longevity Economy. Generating economic growth and new opportunities for 
business. Retrieved from https://www.aarp.org/content/dam/aarp/home-and-family/personal-technology/2013-10/Longevity-Economy-Generating-NewGrowth-AARP.pdf

RoboticsBIZ. Top seven companion and social robots for elderly people. Retrieved from https://roboticsbiz.com/ top-seven-companion-and-social-robots-for-elderlypeople/

Rzeczynski, B. (2009). Gerontechnologia w przestrzeni komunalnej [Gerontechnology in communal space]. Przeglad Komunalny, 3, 86-87.

Sale, P. (2018). Gerontechnology, Domotics and Robotics. In S. Masiero \& U. Carraro (Eds.), Rehabilitation Medicine for elderly patients (pp. 161-169). Springer International Publishing. doi:10.1007/978-3-319-57406-6

Simsik, D. (2012). The Mechatronic Shoe: A new Rehabilitation, 29th International Symposium on Automation and Robotics in Construction. 8th World Conference of the International Society for Gerontechnology. doi: 10.22260/ISARC2012/0070

Szpilko, D. (2020). Foresight as a tool for the planning and implementation of visions for smart city development. Energies, 13(7), 1782. doi: 10.3390/en13071782

Tellier, M., Auger, C., Bier, N., \& Demers, L. (2020). Use of an electronic pillbox by older adults with mild Alzheimer's disease: Impact on medication administration and adherence. Gerontechnology, 19(1), 66-76. doi: 10.4017/gt.2020.19.1.007.00

United Nations. (2019). Word Population Ageing 2019 Highlights. Retrieved from https://www.un.org/en/ development/desa/population/publications/pdf/ageing/WorldPopulationAgeing2019-Report.pdf

Wieczorek, A. (2016). Gerontechnologia w rozwiązywaniu problemów osób starszych [Gerontechnology in solving problems of the elderly]. Systemy Wspomagania w Inżynierii Produkcji, 2(14), 358-370.

Zimnoch, K. (2013). Starzenie się i srebrna gospodarka w uwarunkowaniach rozwojowych Podlasia [Aging and the silver economy in the development conditions of Podlasie]. Optimum. Studia Ekonomiczne, 4(64), 2536. 